\title{
O Futuro das relações Brasil-EUA: aspectos de segurança'
}

1. Palestra proferida na UnB, durante o Seminário das Relações Brasil/EUA, em 19/11/81.
Para extrair conclusões confiáveis sobre as relações Brasil-EUA sob a perspectiva da segurança, é preciso que delineiemos antes o quadro dessas relações, procurando definir seus fundamentos e fatores condicionantes. Ėo que farei agora, pedindo-lhes que me relevem uma certa ênfase naval que imprimo ao assunto, ênfase essa que decorre da visão profissional a que estou sujeito.

O Tratado Interamericano de Assistência Recíproca (TIAR), sucessor e continuador dos Acordos inspirados pela ameaça do Eixo, tem sido a moldura formal das relações americanas no campo da segurança, inclusive das relações brasileiro-norte-americanas, desde sua assinatura em 1947. Para a maioria dos países latino-americanos, então traumatizados pela Segunda Guerra Mundial, esse Tratado era um instrumento de defesa contra uma ameaça clássica como a que havia recentemente superada, ressaltando na época a URSS como o mais provável agressor. Já os EUA viam no TIAR um instrumento da política de contenção do expansionismo comunista, instituída pelo Governo Trumman, não se limitando sua utilidade aos casos de agressão clássica.

Essa imprecisa unidade de perspectiva produziu reflexos não apenas nas raras ocasiões em que o Tratado foi invocado, quando surgiram dificuldades oriundas da interpretação do conceito de agressão, mas também no desenvolvimento dos Acordos de Assistência Militar que, inspirados pelo agravamento da tensão decorrente da guerra da Coréia e dos problemas revolucionários alimentados pela URSS, inclusive na América Latina, acabaram se configurando como desdobramentos práticos do TIAR. Lembro-lhes que o referente ao Brasil foi assinado em 1952.

Efetivamente, o governo norte-americano, sócio maior e fiador da assistência, sempre condicionou sua política de apoio às Forças Armadas latino-americanas à sua perspectiva do problema da segu- 
rança continental, que só reconhecia uma ameaça: o expansionismo comunista, que se manifestava por modalidades diversas, da agressão militar à tomada legal do poder político, passando pela subversão e a guerra revolucionária. Dessa forma, o conjunto de medidas de apoio, envolvendo o fornecimento de material, a instrução e o adestramento, era planejado e executado para reforçar os governos próocidentais e para ajustar o preparo e os conceitos de emprego dos poderes militares latino-americanos à visão estratégica dos EUA. Tal orientação teria que gerar resultados polêmicos, na medida em que algumas preocupações de segurança dos países latino-americanos deixassem de ser pautadas pelo confronto Leste $\times$ Oeste, o que realmente ocorreu em décadas posteriores.

No que concerne ao Brasil, até o início dos anos 60 a orientação norte-americana a que acabo de me referir beneficiou a Marinha e, em particular, sua parcela destinada à guerra anti-submarino, pois a ameaça submarina era, então, como ainda é hoje, o principal instrumento militar convencional soviético para agressões além do alcance do Exército Vermelho. Chamo a atenção para esse ponto, talvez demasiado especializado para este Seminário, porque a ênfase antisubmarino, praticamente exclusiva, a que foi conduzida a Marinha Brasileira, é um exemplo de orientação estratégica influenciada por um apoio comandado do exterior.

Entretanto, é oportuno observar que, apesar da inegável maior relevância da posição brasileira no Atlântico e da disparidade das dimensões físicas e demográficas, a transferência de meios e a oferta de facilidades de instrução e adestramento foram sempre estendidas, de forma praticamente equitativa, à Argentina e ao Chile, numa demonstração de que os EUA não desejavam criar um desbalanceamento que pudesse vir a alimentar antagonismos regionais, que uma grande potência não se permite admitir em sua área de influência, numa época de crise grave. Essa orientação, compreensível e lógica para os EUA, não podia deixar de gerar algum ressentimento, já que nosso engajamento, ponderável e franco, não era retribuído em termos coerentes com a participação relativa do Brasil.

No início de 1963, ocorreu um acontecimento que introduziu a primeira fissura no íntimo relacionamento militar entre o Brasil e os EUA, que prevalecia desde 1942. Refiro-me ao confronto entre a França e o Brasil, em torno da explotação de recursos marinhos na plataforma continental brasileira. Os EUA mantiveram atitude discreta no episódio e, se houve pressão sobre a França, quando aquele país ameaçou usar seu poder naval em apoio aos interesses pesqueiros, essa pressão nunca foi revelada. Entretanto, é obvio que os EUA não podiam ver com simpatia os navios de combate transferidos ao Brasil sob o patrocínio de um Acordo inspirado pela ameaça soviéti$\mathrm{ca}$, empregados numa tarefa que, mais cedo ou mais tarde, iria colidir contra interesses econômicos norte-americanos. Isso veio realmente a ocorrer e tem sido um desagradável motivo de inquietação, pois dificuldades dessa natureza abalam a confiança necessária a um bom relacionamento no campo da segurança.

Temo que esse problema possa tornar-se mais grave, se a atual Conferência, conduzida sob os auspícios da ONU e destinada a regu- 
lar o Direito Internacional Marítimo, não chegar a um bom termo. Lembro-Ihes que, infelizmente, o "endurecimento" da posição norteamericana após a assunção do Presidente Reagan veio comprometer a esperança de uma breve solução para alguns temas controvertidos, solução essa já praticamente delineada e aceita ao tempo do Governo Carter.

Voltando ao relacionamento Brasil-EUA, creio que merece agora um registro especial a revisão da política de segurança efetivada no Governo Kennedy, que prescreveu, como principal ameaça no Hemisfério Ocidental ao sul dos EUA, a constituída pelos movimentos revolucionários e subversivos, aos quais Cuba começava a proporcionar alento moral e, por vezes, apoio direto. Em conseqüência dessa avaliação, o apoio norte-americano no campo da segurança passou a enfatizar a transferência de material, a instrução e o adestramento relacionados com as operações de segurança interna - o que, é claro, tendia a beneficiar mais os Exércitos e as parcelas da Força Aérea e, secundariamente, da Marinha, destinadas ao apoio à força terrestre.

Aliás, é válido observar aqui que, talvez em decorrência da perspectiva norte-americana a respeito do problema do Hemisfério Ocidental, o "Southern Command", Grande Comando Combinado dos EUA com responsabilidade sobre as Américas Central e do Sul, é chefiado por um general do US Army, cabendo-lhe difundir táticas e técnicas de contraguerrilha e de assistência cívico-social e apoiar o preparo dos Exércitos latino-americanos para o cumprimento dessa parcela de suas missões. Com tal orientação, os EUA, além de implementarem medidas que consideram adequadas para o confronto Leste $\times$ Oeste, evitam reforçar a capacidade militar clássica dos Exércitos latino-americanos - o que poderia facilitar o ressurgimento de antagonismos locais. É justo que se diga, porém, que a Marinha do Brasil e outras Marinhas regionais pouco sofreram com o reajuste do apoio e a ênfase antiguerrilha, pois a revisão efetivada por McNamara manteve como parâmetro merecedor de preocupação a ameaça submarina soviética ao tráfego marítimo interamericano.

Um curioso e sintomático reflexo da política norte-americana instituída por McNamara é o que emerge nas reuniões periódicas que congregam altos chefes militares americanos. Refiro-me ao fato de que nas reuniões de chefes navais a guerra clássica costuma ser um tema relevante, ao contrário do que se passa nas reuniões de chefes terrestres, numa demonstração de que os EUA não concedem prioridade a um papel clássico para os Exércitos latino-americanos no confronto Lestex Oeste, que condiciona seu apoio.

No fim dos anos 60 e início dos 70 , ocorreu uma evolução importante no campo do relacionamento de segurança entre o Brasil e os EUA, evolução essa cujas raízes podem ser identificadas na relativa falta de vigor da unidade conceitual do TIAR, a que me referi no início de minhas palavras.

Naqueles anos, uma série de acontecimentos, idéias, tendências e fatos conduziu-nos a um modesto início de diversificação do nosso preparo militar, à revelia dos EUA, cujas Forças Armadas relutaram em apoiar a mudança, como bem comprova a dificuldade en- 
frentada para variar o quadro essencialmente anti-submarino da tradicional operação UNITAS. Dentre os motivos que justificaram a mudança, merecem destaque o degelo da guerra fria, a consolidação de nossa segurança interna (que estivera abalada em anos anteriores), a paulatina crescente percepção de que precisávamos preocupar-nos com alguns aspectos da segurança nacional e do emprego do poder militar que transcendem a segurança interna e a proteção antisubmarina do tráfego marítimo costeiro e, finalmente, o sentimento de que se fazia necessário reduzir a dependência logística externa vinculada aos Programas do Acordo de 1952, dependência que era, insisto, uma forte influência na configuração de nossas Forças Armadas e em suas concepções de emprego.

Isso tudo e a persistente resistência norte-americana contra o fornecimento de material moderno explicam a compra de aviões à França, de fragatas e submarinos à Inglaterra, de navios-varredores de minas à Alemanha e de equipamentos diversos de origem européia para o Exército. Explicam, também, o esforço que vem sendo desenvolvido em proveito de uma incipiente indústria militar brasileira, cuja implantação é indispensável para que nosso poder militar mereça credibilidade como instrumento de apoio à consecução de políticas e estratégias próprias, não, necessariamente, coincidentes em toda a linha com as da potência preponderante na área geográgica e cultural em que nos inserimos.

Os alicerces do Acordo de Assistência Militar de 1952, assim solapados, acabaram por ruir em 1977, tendo sido seus últimos algozes a política do Governo Carter em relação aos países onde, a seu juízo, havia desrespeito aos direitos humanos, bem como a hostilidade daquele governo ao programa nuclear brasileiro.

A denúncia do Acordo de 1952 vinha, aliás, ao encontro da corrente de opinião que o julgava prejudicial para a modernização de nossas Forças Armadas, em função de uma política de segurança própria. Creio que só a perspectiva do tempo permitirá um julgamento completo e sereno a esse respeito porque, é justo que se diga, o Acordo nos foi temporariamente útil e respondeu à pressão preponderante e peculiar de uma época crítica.

Note-se, porém, que mesmo após a denúncia do Acordo, a US Navy procurou reduzir os efeitos dos rumos da política porque, no final dos anos 70, a dimensão estratégica do Atlântico Sul prosseguia crescendo, já agora não apenas devido ao tráfego marítimo, que as crises do Oriente Médio e o gigantismo dos petroleiros haviam desviado de Suez, mas também porque o aperfeiçoamento dos mísșeis balísticos começava a permitir o posicionamento dos submarinos do sistema nuclear estratégico da URSS emáguas mais distantes do que as do Atlântico Norte e Ärtico. Essa visão naval do problema fez com que continuassem a ser realizadas anualmente as operações UNITAS, último vestígio da cooperação anterior.

Neste ponto, chegamos finalmente às extrapolações para o futuro, que procurarei relacionar com o que disse até agora e fundamentar nas tendências e nos fatos conhecidos ou provavéis. 
A evolução do relacionamento Brasil-EUA no campo da segurança no futuro breve deverá ser fundamentalmente influenciada pelos seguintes fatores:

a) o aumento das preocupações norte-americanas com o Atlântico Sul, em virtude da crescente importância das rotas marítimas austrais e do posicionamento de submarinos do sistema nuclear soviético, a que já fiz menção anterior, bem como da interveniência soviética e cubana na África;

b) o ressurgimento de alguns sintomas típicos da guerra fria dos anos 50 e 60 , oriundos, em parte, das posições "duras" assumidas pelo Governo Reagan;

c) o abrandamento da atitude norte-americana no controvertido campo dos direitos humanos, que pode ter decorrido tanto de uma reavaliação dos julgamentos anteriores, como da prevalência do estratégico sobre o humanitário, como ocorreu em relação ao Irã de Reza Pahvlavi, até mesmo no período messiânico dos primeiros anos de Carter;

d) a percepção pelos EUA de que o poder militar brasileiro procura flexibilizar sua orientação, que estivera condicionada por três décadas de apoio norte-americano, buscando em fontes européias o que o país não produz; e

e) a evolução do nosso relacionamento no campo econômico, cujas dificuldades nos afligem hoje prioritariamente, parecendo-me óbvio que o relacionamento de segurança não poderá ser beneficiado à revelia de algo similar na área econômica.

Todos esses fatores são importantes, mas é provável que as preocupações do campo econômico sejam as primordiais para a atitude brasileira, cabendo ao Atlântico Sul posição similar no que concerne à norte-americana, ao menos enquanto se mantiver satisfatória a segurança interna na América Latina, cuja relativa tranqüilidade dos anos recentes não chega a ser seriamente abalada por episódios como a revolução nicaragüense e a guerrilha salvadorenha.

Essa idéia de que a política de segurança norte-americana em relação ao Brasil será ponderavelmente influenciada pelo que se passa no Atlântico Sul pode ser melhor entendida analisando-se a situação do nosso país nesse oceano, onde ele se destaca em virtude:

a) da sua excelente posição, debruçada, ao norte, sobre o flanco sul do teatro do Atlântico Norte (OTAN) e, a leste, sobre as rotas que interligam o Oriente Médio, a Âfrica e a América do Sul à Europa eaos EUA (inclusive a rota do petróleo do Oriente Médio); e

b) da estabilidade política e tendência ocidentalista do Brasil, às quais se associa a já razoável dimensão do poder nacional brasileiro.

Em complemento, vale ressaltar que, ressalvadas a Argentina, país geoestrategicamente um tanto excêntrico sob a perspectiva do tráfego marítimo do İndico para o Atlântico Norte, e a África do Sul, cujo concurso formal e ostensivo está severamente inibido pela política do "apartheid" e pelo impasse na Namíbia, não existem ao sul do 
paralelo de Dakar outros países capazes de exercer um papel relevante no Atlântico Sul. Essa é a situação de curto prazo, embora a prazo mais longo se possa esperar que alguns países da África Negra venham a conseguir estabilidade e progresso que os credenciarão para um papel sensível; lembro que, atualmente, até mesmo o papel de posição de apoio é inseguro - valendo ressaltar que essa afirmação é válida tanto para o Ocidente como para a URSS.

É compreensível e previsível, portanto, que o Brasil deva ser objeto de ponderável atenção, na política de segurança dos EUA para o Hemisfério Sul. Entretanto, a despeito de todos os fatores que insinuam o caminho do bom entendimento, pessoalmente eu creio que não mais pode se repetir o passado que nos foi compelido pela ameaça do Eixo e, em certa medida, pela preocupação anti-soviética do período crítico da guerra fria.

Lembro-thes que em 1942 nosso despreparo nos obrigou a aceitar, além do fornecimento de material, a montagem de um sistema de apoio dos EUA em nosso território e o controle norte-americano sobre as operações da Marinha e da Força Aérea Brasileira, até mesmo em nossas águas litorâneas. Nos anos 50 , a ameaça soviética, associada a um relativo despreparo a que nos havia conduzido a descontração dos anos imediatamente posteriores a 1945, levou-nos novamente a receber um apoio norte-americano que trazia embutido em seus instrumentos uma orientação subliminar ou mesmo ostensiva. Esses tipos de alinhamento dificilmente seriam aceitos, na presente conjuntura brasileira.

Efetivamente, começamos a consolidar a idéia de que nossa política de segurança não mais pode continuar fundamentalmente sujeita a uma visão hegemônica de segurança continental; reconhecemos a inexorabilidade dessa influência, mas é preciso que ela atente para nossos interesses relevantes, a fim de que seja aceitável. Começamos, também, a sentir que nosso poder militar precisa ser resguardado por um nível mínimo de nacionalização, para que ele seja um instrumento eficaz a serviço da política nacional. Em complemento, estamos nos habituando com a idéia de que é viável viver à revelia de um grande apoio norte-americano, ainda que com algum sacrifício para o aparelhamento de curto prazo. Já não mais nos conformamos com situações que impliquem em detrimento do comando e controle brasileiros, em nosso território e em águas próximas. Finalmente, sentimos que não podemos adotar orientações ou políticas de segurança que possam pôr em risco outras parcelas da política nacional, que, na presente conjuntura, apresentam alto peso específico. Qualquer relacionamento que não leve em consideração essas tendências, dificilmente terá sucesso.

Evidentemente, somos partícipes da cultura ocidental e de seus valores, somos do Ocidente e estaremos alinhados com o Ocidente, caso se concretize o conflito Leste $\times$ Oeste. Contudo, isso não nos compele a pautar.nossa conduta e nossas concepções de segurança exclusivamente em função de um confronto global em que somos atores secundários, pois temos hoje várias preocupações de natureza política e econômica que não nos autorizam o engajamento, irrestrita 
e permanentemente, em tal confronto. Nosso grande objetivo atual de segurança é a manutenção da tranqüilidade necessária ao nosso desenvolvimento, condição indispensável para que vençamos os óbices que se opõem ao bem-estar de nosso povo. Esse macroobjetivo de segurança exige, é claro, alguns cuidados relacionados com a preocupação dominante nos EUA, cuidados esses que têm sido devidamente considerados e continuarão a sê-lo. Entretanto, nada nos indica que eles são incoerentes com nossa presente política de segurança, cuja alteração poderia induzir dificuldades para o nosso desenvolvimento.

A idéia que acabo de expor é um reflexo fiel da política inferida de uma declaração conjunta dos presidentes da Argentina e do Brasil, referente ao Atlântico Sul, com a qual encerro minhas palavras. Disseram os Presidentes Viola e Figueiredo, a 26 de maio último, que é conveniente manter o Atlântico Sul a salvo de tensões e confrontações internacionais, de modo a preservar seu caráter de instrumento pacífico do intercâmbio e do desenvolvimento das nações que o margeiam. Creio que essa declaração sintetiza com rigor o que acabo de apresentar-lhes e esboça o que podemos esperar no futuro breve, quanto às relações Brasil-EUA, sob a perspectiva da segurança. 